\title{
EDITORIAL
}

\section{Construindo a educação profissional no contexto amazônico}

\author{
Deuzilene Marques Salazar \\ https://orcid.org/0000-0003-1927-1399 \\ Tiago Veloso dos Santos \\ https://orcid.org/0000-0001-9394-7575
}

A EPT em Revista publica esta edição especial, em formato de dossiê, com objetivo de discutir a analisar as perspectivas e possibilidades da Educação Profissional e Tecnológica na região Norte do Brasil, considerando a particularidade e singularidade de processos educativos no contexto amazônico com vistas ao desenvolvimento social e econômico da região.

A diversidade é uma característica da região amazônica. Diversidade quanto às condições de vida local, de saberes, de valores, de práticas sociais e educativas, bem como de uma pluralidade humana representada por diferentes sujeitos sejam camponeses, ribeirinhos, quilombolas, indígenas e imigrantes e sua distribuição pela vasta extensão geográfica que a constitui. Esta diversidade impõe desafios, o de construir sua própria identidade, numa busca de não sucumbir aos modelos impostos de fora, que muitas vezes veem e utilizam a região como espaço de exploração das riquezas naturais e do conhecimento da população local.

Diante deste contexto, reunir estudos e pesquisas sobre a educação profissional na região Norte do Brasil é uma tarefa complexa, considerando este cenário de condições difíceis, muitas vezes extremas. As contradições se evidenciam nas condições mais básicas para o trabalho educativo e pedagógico como, por exemplo, no fornecimento de água, de energia elétrica, acesso a rede de telefonia e de internet em muitos espaços formais e não formais de educação.

A questão inicial que colocamos em debate consistiu em: o que caracteriza ou define a expressão "contexto amazônico" nesse dossiê? Entendemos que o uso desta expressão busca superar a perspectiva fragmentada e parcial e torná-lo como produto de múltiplas determinações históricas, sociais e culturais articuladas no tempo e no espaço. 
Dessa forma, entendemos que a educação não pode ser isolada da sua intencionalidade e finalidade a qual se destina e, portanto, extrapolam os territórios nos quais elas são realizadas.

Compreendemos que o local não pode prescindir do regional, do nacional, e até mesmo do global. Acreditamos na articulação entre o singular e o universal para o melhor entendimento da dinâmica da educação em diferentes territórios que explicitam as diversidades e singularidades presentes nesses espaços geográficos que se encontram em processo de construção. Portanto, não há um contexto amazônico "cristalizado" mas em constante processo de mudança. Assim, o que socializamos neste Dossiê são pequenas porções do que convencionamos intitular de educação no contexto amazônico.

Abre o conjunto de textos dessa edição o artigo "Educação e mundo do trabalho: algumas contribuições para o debate" no qual a autora, sob a perspectiva do materialismo histórico-dialético, expõe alguns elementos para o debate sobre as propostas de formação do profissional estabelecendo uma relação com as pedagogias contemporâneas e os modos de produção capitalista.

Em seguida, o artigo "A presença dos conhecimentos indígenas no ambiente educacional formal: o que pensam os alunos?, apresenta uma análise dos entendimentos que um grupo de alunos do curso Técnico em Informática Integrado ao Ensino Médio, do Instituto Federal de Rondônia (IFRO), campus Ji-Paraná, possui a respeito da temática indígena no âmbito escolar, em especial as suas corporalidades, e a sua presença na disciplina de Educação Física. Os autores discutem que as corporalidades no contexto indígena possibilitam entender a sua organização social, a sua cosmologia, os seus rituais, ou seja, permitem que compreendamos minimamente a estrutura e funcionamento sociocultural de uma determinada etnia. Assim, defendem que compreender e aprender com o pensamento indígena é primordial para desenvolver relações mais equânimes na sociedade em que todos estamos inseridos.

As práticas corporais no âmbito do ensino são o objeto de análise do artigo “Trekking como prática pedagógica em espaços amazônicos: uma perspectiva aos Institutos Federais". Compreendendo a importância das práticas corporais enquanto conteúdo da educação física escolar, carregadas de significados e com grande potencial crítico social, além de aspectos cognitivos, o texto apresenta a perspectiva do Trekking, definido como uma caminhada por ambientes naturais, como possibilidade de trabalhar 
o conteúdo nas aulas e aproximar o ensino e espaços naturais amazônicos. Essa contribuição significativa do Instituto Federal de Educação, Ciência e Tecnologia do Acre, caracteriza-se como prática pedagógica interdisciplinar no ensino médio integrado, desenvolvendo além dos aspectos físicos, uma educação ambiental crítica através do uso de espaços amazônicos.

No estudo "Politecnia e currículo integrado na Rede Federal de Ensino: contextos e desafios na educação profissional e tecnológica integrada de nível médio" os autores discutem, por meio de pesquisa bibliográfica, a relação entre politecnia e currículo integrado na atual configuração da Rede Federal de Educação Profissional, Científica e Tecnológica. O texto, produzido no Instituto Federal de Educação, Ciência e Tecnologia do Amazonas, contextualiza a história e os desafios para a implementação de um currículo que integre a educação básica e profissional, apresentando as origens da Rede Federal de Ensino no Brasil e as políticas adotadas em relação a Educação Profissional Técnica de Nível Médio. Com base nisso, conclui que mudanças legislativas a partir do início dos anos 2000, possibilitaram a integração da Educação Básica à Educação Profissional inspirada no ideário da politecnia, ressaltando a necessidade da continuidade das ações que promovam a real integração curricular visando um ensino politécnico que auxilie na emancipação da classe trabalhadora.

Apresentando uma discussão das categorias trabalho e linguagem como bases ontológicas para o desenvolvimento do homem, o artigo "O trabalho e a linguagem na constituição do ser humano" destaca a relevância da formação humana omnilateral no Ensino Médio Integrado à Educação Profissional e Tecnológica (EPT) bem como enfatiza o papel da produção da linguagem no trabalho e na vida dos estudantes. Assim, os autores analisam a prática do ensino textual em turmas do ensino médio integrado do Instituto Federal do Tocantins. Os autores destacam o trabalho e a linguagem como categorias decisivas do processo de desenvolvimento humano, posto que elas são essenciais na articulação com a cultura, com a ciência e suas tecnologias.

O texto "Variações linguísticas no processo de ensino-aprendizagem da língua espanhola na fronteira Brasil-Bolívia", produzido no Instituto Federal de Educação, Ciência e Tecnologia de Rondônia, analisa as variações linguísticas da língua espanhola na cidade de Guajará-Mirim - fronteira do Brasil com a Bolívia e suas implicações para o ensino e aprendizagem de espanhol como segunda língua na região. 
A experiência do ensino em uma região de fronteira internacional possibilita aos alunos o conhecimento da diversidade linguística do espanhol, visando a valorização da variação linguística presente na região. $\mathrm{O}$ estudo busca contribuir com o processo de ensino aprendizagem, promovendo a motivação e interação dos alunos estudantes da língua espanhola na região da fronteira.

A formação politécnica na qual o trabalho se constitui como dimensão ontocriativa mediado pelo conhecimento, ciência e tecnologia é discutido no estudo "Formação politécnica: uma análise dos projetos pedagógicos do curso do IFAM". Os autores mediante a análise dos objetivos do curso e o perfil do egresso definidos nos projetos político-pedagógicos do curso técnico de informática nas modalidades integrado e subsequente dos campi da I Fase de Expansão da Rede Federal no Instituto Federal de Educação, Ciência e Tecnologia do Amazonas (IFAM), constatam que, embora a Educação Profissional e Tecnológica defenda o desenvolvimento das diferentes dimensões do ser humano - sobretudo a partir da integração entre os conhecimentos intelectuais e os práticos -, ainda existe um hiato em documentos que direcionam a efetividade da proposta de educação politécnica.

O trabalho "O uso do Scratch como ferramenta para o ensino de química orgânica", produzido no Instituto Federal de Educação, Ciência e Tecnologia do Pará, parte do reconhecimento cada vez maior da relevância da tecnologia no cenário educacional e compartilha uma experiência da aplicação de um jogo com docentes para o ensino de Química Orgânica, no sentido de minimizar as dificuldades encontradas ao lecionar Química em uma escola cada vez mais interligada a um contexto educacional voltado para o uso da tecnologia. A validação do jogo, realizada através da aplicação de questionário para docentes da área de química possibilitou conhecer o grau de aceitação do jogo e mostrou a ampla aceitação da ferramenta para tornar as aulas mais atrativas para o alunado.

Ainda na esteira da discussão sobre a docência, no artigo "Acolhimento institucional e integração docente: articulação necessária ao início da docência na educação profissional no extremo oeste da Amazônia" os autores analisam as percepções dos docentes sobre os processos de acolhimento, integração e os impactos vivenciados em sua prática pedagógica no Instituto Federal do Acre, Campus Cruzeiro do Sul. Por meio de investigações bibliográficas, documentais e entrevistas com os 
docentes nas diferentes áreas de conhecimento, básicas e técnicas, os autores defendem a presença do acolhimento nas ações da gestão dos IFs, pois, com tais ações os docentes ingressantes se sentirão acolhidos, mais seguros e confiantes tanto na construção quanto na efetivação de sua prática educativa.

A análise de evidências da formação humana integral nos documentos orientadores da internacionalização da educação profissional e tecnológica no âmbito do Instituto Federal de Educação, Ciência e Tecnologia do Amazonas (IFAM) fomentou o estudo “A formação humana integral nas diretrizes para a internacionalização no IFAM". Os autores na verificação de duas resoluções que tratam do programa de bolsas IFAM internacional e do regimento interno do Centro de Idiomas implantado no instituto, evidenciaram inicialmente o processo de internacionalização das políticas educacionais e sua efetivação na Rede Federal de Educação Profissional, Científica e Tecnológica (RFEPCT). Por fim, os autores indicam a necessidade de avaliar a internacionalização da educação profissional e tecnológica numa perspectiva de desenvolver a educação omnilateral do sujeito tendo por base os princípios da politecnia e da escola unitária.

As produções bibliográficas aqui apresentadas representam um esforço coletivo das Coordenações do Curso de Mestrado em Educação Profissional e Tecnológica que articulados aos docentes e discentes incitaram discussões e estudos sobre a temática do dossiê. Assim, fica aqui nosso agradecimento e reconhecimento pelo trabalho e compromisso com os processos formativos da educação profissional e tecnológica em seus diferentes espaços e configurações. Registramos aqui nossa gratidão a todos que compartilharam conosco suas produções.

Convidamos você a conhecer um pouco mais das especificidades e singularidades de nossa Região. Desejamos a todos uma boa leitura.

Manaus, Belém, março de 2020. 